\title{
Epidermal Growth Factor Receptor, Somatostatin and Bcl-2 in Human Pancreatic Tumor Xenografts
}

\author{
An Immunohistochemical Study
}

Attila ZALATNAI

First Institute of Pathology and Experimental Cancer Research, Semmelweis University of Medicine, Budapest, Hungary

Xenografted human pancreatic tumors (5 ductal adenocarcinomas, 1 leiomyosarcoma, altogether 26 samples) were investigated about their immunohistochemical expression of epidermal growth factor receptor (EGFR), somatostatin (SS) and bcl-2 protein. The expression of the EGFR varied from tumor to tumor. One originally negative carcinoma became immunoreactive during passagings, one tumor has lost its early positive expression, and in 3 cancer lines a phenotypically constant pattern was seen. SS immunoreactivity was practically absent in all tumor samples. Concerning bcl-2 expression, different staining patterns were observed among the carcinomas, but the leiomyosarcoma has retained its strong positivity during xenograftings. In the PZX-5 carcinoma line that was originally negative, the onemonth Sandostatin treatment induced the strong expression of bcl-2 protein suggesting a development of an acquired resistance against programmed cell death in this tumor. (Pathology Oncology Research Vol 5, No 2, 146-151, 1999)

\section{Introduction}

Epidermal growth factor (EGF) is recognized as a growth-stimulatory factor for pancreatic carcinoma. ${ }^{420,28,30}$ In BOP-induced pancreatic carcinogenesis experiments in hamsters it exhibited a cocarcinogenic effect, ${ }^{4}$ and the proliferation of different human pancreatic cancer cell lines has also shown to be stimulated by $\mathrm{EGF}^{7,20,30}$ In pigs EGF induced hyperplastic lesions in the large interlobular ducts, accompanied by increased number of PCNA-positive nuclei. ${ }^{31}$ EGF acts through its receptor (EGFR), a $170 \mathrm{kD}$ transmembrane glycoprotein.

Received: Jan 22, 1999; accepted: April 10, 1999

Correspondence: Attila ZALATNAI, M.D., Ph.D., First Institute of Pathology and Experimental Cancer Research, Semmelweis University of Medicine, Üllői út 26., H-1085 Budapest, Hungary, Tel.: +(36)-1-266-1638, fax: +(36)-1-317-1074;

E-mail: zalatnai@korb1.sote.hu

This work was supported by the Hungarian Scientific Research Fund (OTKA T 23697) and by the Hungarian Cancer Foundation Abbreviations: EGFR $=$ epidermal growth factor receptor; $\mathrm{SS}=$ somatostatin; $\mathrm{PBS}=$ phosphate buffered saline; $\mathrm{DAB}=3,3$ ' diaminobenzidine; $\mathrm{BOP}=\mathrm{N}$-Nitrosobis(2-oxopropyl)amine
In normal human pancreas a weak immunoreactivity of EGFR was found only in the endocrine part of the organ, while the ductal system was free of EGFR. This pattern, however, changed in various diseases. In chronic pancreatitis, for example, both the centroacinar cells and the large ducts displayed strong cytoplasmic reaction. ${ }^{10}$ Similarly, over $95 \%$ of ductal adenocarcinomas showed positivity, but there was no apparent relationship to tumor grade or histologic type. ${ }^{10}$

Somatostatin (SS) is found in the D cells of the Langerhans islets, but scattered SS-positive cells are interspersed among the ductal cells, as well. In the past decade it has become obvious that the pancreatic carcinomas of non-endocrine origin could also respond to hormonal manipulations. Synthetic analogs of SS may inhibit the growth of experimentally induced tumors ${ }^{25,40}$ and xenografted pancreatic carcinomas. ${ }^{16,18,29}$ The administration of a SS-analog Sandostatin (octreotide) has also been supported by a number of experiments. ${ }^{17,26,35}$ In clinical studies prolonged survival could be achieved with combined treatment of octreotide and tamoxifen. ${ }^{21}$ Moreover, somatostatin receptor mRNAs have recently been demonstrated in human pancreatic cancer samples. ${ }^{5}$ 
Bcl-2 protein, a $25 \mathrm{kD}$ product of the bcl-2 gene is known as an inhibitor of the programmed cell death (apoptosis) and it is expressed in various malignant tumors. ${ }^{9,14,22,24,36,37}$ On pancreatic malignancies, however, only few published data are available. Wang et al. ${ }^{34}$ reported $45 \%$ of immunostaining positivity in pancreatic neuroendocrine tumors. In ductal adenocarcinomas bcl-2 positivity ranged from $20-55 \%$, but the correlation of these data with the prognosis is still unclear. ${ }^{11,15,23}$

Expression of the EGFR, somatostatin and bcl-2 have never been studied in human pancreatic cancer xenografts before. Our aim was to assess the immunoreactivity of these antigens in the early and late passages of our newly established human pancreatic tumor xenografts grown in artificially immunosuppressed mice.

\section{Materials and Methods}

\section{Pancreatic tumor xenografts}

Five human pancreatic ductal adenocarcinomas (PZX-2, PZX/5, PZX-11, PZX-16, PZX-20) and 1 pancreatic leiomyosarcoma line (PZX-7) have been established. Their detailed characteristics have been published elsewhere. ${ }^{3,38,39}$ Briefly, human pancreatic tumors or pancreatic tumor metastases were inoculated subcutaneously into immunosuppressed CBA/CA mice and after taking the tumor fragments were further transplanted. These successfully established tumor lines have been maintained for 18 to 32 months. For immunohistochemical studies the archived original tumor and samples from the late passages have been used.

\section{Sandostatin-treatment}

In the 4th passage of PZX-5 tumors a hormonal treatment (octreotide acetate, Sandostatin; NOVARTIS) was performed. The tumor-bearing animals have been treated with $2 \times 500 \mu \mathrm{g} / \mathrm{kg}$ body weight Sandostatin given intraperitoneally for 1 month.

\section{Immunohistochemistry}

The $5-\mu m$-thick sections from formalin-fixed, paraplast-embedded materials were deparaffinised, e hydrated and endogenous peroxidase was blocked by $3 \% \mathrm{H}_{2} \mathrm{O}_{2}$ for $10 \mathrm{~min}$. After rinsing with PBS, primary antibodies raised against the following antigens were applied (all antibodies were from BioGenex): epidermal growth factor receptor (polyclonal, epitope specific, Cat. No. AR335-5R) for 2 hours; somatostatin (polyclonal, Cat. No. AR042-5R) for $30 \mathrm{~min}$ and bcl-2 protein (monoclonal, Cat. No. AM287$5 \mathrm{M}$ ) for $30 \mathrm{~min}$. Before applying bcl-2 primary a $5 \mathrm{~min}$ microwave antigen retrieval procedure was performed (Meditest MFX 800-2) in 0.01 M citrate buffer (pH 6.0).
As a detection system a Super Sensitive MultiLink kit was used utilizing biotin-streptavidin (B-SA) formula and $\mathrm{DAB}$ as a chromogen. For positive controls normal pancreas (SS), breast cancer (EGFR) and normal tonsil (bcl-2) were used.

Intensity of the reactions was scored at a semiquantitative scale: - no reaction, \pm vague reaction, + mild reaction, ++ moderately strong reaction, +++ strong reaction.

\section{Results}

The degree of differentiation and the immunohistochemical results are summarized in Table 1 .

The various adenocarcinomas displayed different EGFR patterns. In the PZX-2 the original tumor proved to be negative, but after the 5th passage the majority of the tumor cells became positive. Conversely, in the PZX-11 tumors the originally strong positivity (Figure 1.) gradually disappeared. In two tumor lines, namely PZX-16 and PZX-20 the early and the late transplants exhibited an unaltered pattern: complete negativity in the former, and retained positivity in the latter (Figure 3.). As it was expected, the leiomyosarcoma (PZX-7) did not express any immunohistochemical positivity for EGFR. All the samples of the PZX-5 line expressed strong EGFR positivity (varying between 75 to $95 \%$ of the cells), and this pattern has remained unchanged after a 1-month treatment with the SS-analog (Figs. 5,6).

Somatostatin immunoreactivity was practically absent in all tumor samples studied both in the early and late passages, just occasionally some vague positive cells were present in individual samples. No alterations were seen after the Sandostatin treatment.

Like the EGFR immunoreactivity, the bcl-2 staining pattern has varied from tumor to tumor. The PZX-2 line was completely negative, while in the PZX-16 and PZX20 lines both the early and the late xenografts exhibited a positive reaction. The originally positive PZX-11 tumor (Figure 2.) has lost this staining property during passaging the tumor samples from the 3rd and 9th generations turned out to be completely negative. The PZX-7 leiomyosarcoma has retained its strong positivity during passagings (Figure 4.).

An interesting phenomenon was observed in the PZX-5 tumor. The original and the control untreated xenograft tumors from the 4th generation were negative for bcl-2. After 1-month of Sandostatin treatment, however, all but one xenografted tumors expressed strong positivity in the majority $(70 \%)$ of the carcinoma cells (Figs. 7,8). This suggests that bcl-2 protein expression could be induced by hormonal treatment. On the other hand, this immunohistochemical expression was unrelated to the effect of the hormone: both the regressive and the unresponsive tumors exhibited positive staining. 
There was no clear-cut relationship between differentiation and expression of EGFR or bcl-2 protein. In the poorly differentiated carcinomas EGFR immunoreactivity was usually absent, but similar findings were also found in well differentiated tumors (PZX-2/0, PZX-16). For bcl-2, negative immunostaining was equally observed both in well differentiated (PZX-2) and moderately differentiated tumors (PZX-5/controls), while it was expressed in a Grade III carcinoma (PZX-16/7).

\section{Discussion}

During the last decades numerous molecular alterations have been described in pancreatic carcinomas, but their stability throughout the successive transplantations has not been investigated. In humans, overexpression of different molecules (EGF, EGFR, p53, cyclin-D1 or Ki-67) was found in 44 to $69 \%$ of cases, but their prognostic significance is low. ${ }^{6}$

EGFR is present in a wide range of normal and malignant tissues. In our study its expression varied from xenograft to xenograft, and there were no unequivocal changes in the early and late passages. Although Lemoine et al. ${ }^{10}$ investigating 84 cases of human pancreatic carcinomas found a $95 \%$ immunohistochemical positivity in malignant cells, other reports claimed about $43 \%$ of expression. ${ }^{28}$ Primary tumors and metastatic foci exhibited practically the same immunostaining (43 and $46 \%$, respectively). ${ }^{28}$ This kind of expression seems to be neither of prognostic nor of differential diagnostic value, because EGFR immunoreactivity is also strong in chronic pancreatitis. ${ }^{10}$ Since the normal pancreatic duct are negative for EGFR, its expression in disease may be a secondary, nonspecific phenomenon. According to our data, the 1-month Sandostatin treatment did not influence the high receptor expression in the tumor samples.

As for the bcl-2 antiapoptotic protein expression, positive and negative xenografts were found in our series, and with exception of one tumor line (PZX-11), the staining pattern remained unchanged during passaging. The PZX-11 line, however, has lost its strong immunohistochemical positivity after the early transplantations. The most important finding appeared in PZX-5 tumors. The controls did not express bcl2 protein, but after Sandostatin treatment 6 of 7 tumors

Table 1. Summary of the immunohistochemical results

\begin{tabular}{|c|c|c|c|c|c|}
\hline \multicolumn{2}{|l|}{ Code } & Grade & EGFR & SS & $b c l-2$ \\
\hline \multicolumn{2}{|l|}{$P Z X-2 / 0$} & I & - & - & - \\
\hline \multicolumn{2}{|l|}{$2 / 5$} & I & $+70 \%$ & - & - \\
\hline \multicolumn{2}{|l|}{$2 / 10$} & I & \pm & - & - \\
\hline \multicolumn{2}{|l|}{$\mathrm{PZX}-7 / 0$} & III & - & - & $++80 \%$ \\
\hline \multicolumn{2}{|l|}{$7 / 2$} & III & - & - & $+60 \%$ \\
\hline \multicolumn{2}{|l|}{$7 / 4$} & III & - & - & $++70 \%$ \\
\hline \multicolumn{2}{|l|}{$7 / 5$} & III & $?$ & - & $+++95 \%$ \\
\hline \multicolumn{2}{|l|}{$\mathrm{PZX}-11 / 0$} & I & $++60 \%$ & - & $++70 \%$ \\
\hline \multicolumn{2}{|l|}{$11 / 3$} & III & \pm & - & - \\
\hline \multicolumn{2}{|l|}{$11 / 9$} & III & - & - & - \\
\hline \multirow{2}{*}{\multicolumn{2}{|c|}{$\begin{array}{r}P Z X-16 / 3 \\
16 / 7\end{array}$}} & I & - & - & + \\
\hline & & III & - & - & $++80 \%$ \\
\hline \multirow{2}{*}{\multicolumn{2}{|c|}{$\begin{array}{r}\mathrm{PZX}-20 / 0 \\
20 / 5\end{array}$}} & I & $++75 \%$ & - & $+90 \%$ \\
\hline & & I & $+40 \%$ & - & $+30 \%$ \\
\hline$P Z X-5 / 1$ & I & II & $+75 \%$ & - & - \\
\hline $5 / 4$ & KS & II & $++75 \%$ & - & - \\
\hline $5 / 4$ & K6 & II & $+++95 \%$ & \pm & - \\
\hline $5 / 4$ & K8 & II & $+80 \%$ & + & - \\
\hline $5 / 4$ & K9 & II & aspec. & - & + \\
\hline$P Z X-5 / 4$ & SS1 & II & $++95 \%$ & - & - \\
\hline $5 / 4$ & SS3 & II & $++80 \%$ & \pm & $+60 \%$ \\
\hline $5 / 4$ & SS5 & II & $+70 \%$ & - & $+50 \%$ \\
\hline $5 / 4$ & SS7 & II & $++90 \%$ & - & $+++80 \%$ \\
\hline $5 / 4$ & SS8 & II & $+++70 \%$ & \pm & $+++80 \%$ \\
\hline $5 / 4$ & SS9 & II & $++70 \%$ & - & $++85 \%$ \\
\hline $5 / 4$ & SS10 & II & $+85 \%$ & - & $++70 \%$ \\
\hline
\end{tabular}


became strongly immunoreactive, the proportion of the positive cells ranged between $50 \%$ to $85 \%$. This means that the hormonal treatment induced bcl-2 expression in an originally negative, non-endocrine pancreatic carcinoma. This result seems to be interesting both theoretically and practically.

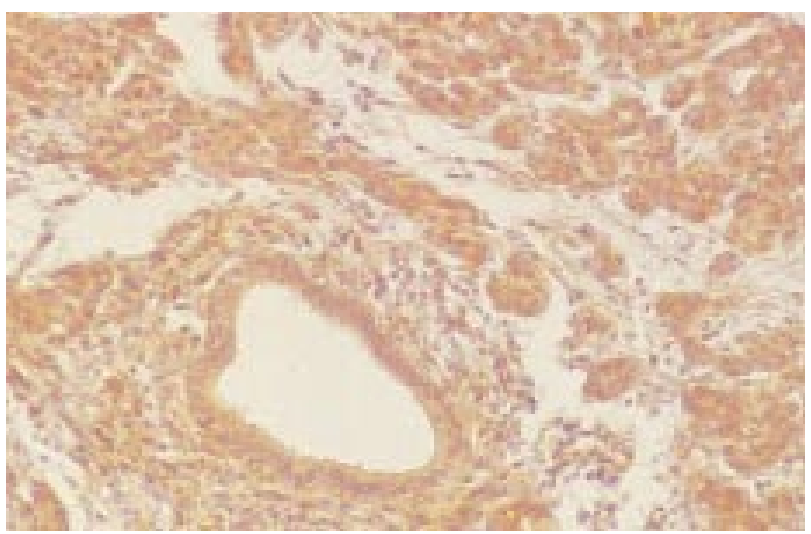

Figure 1. PZX-11, original tumor. Strong epidermal growth factor receptor (EGFR) positivity is shown in the cytoplasm of the tumor cells. $(x$ 100)

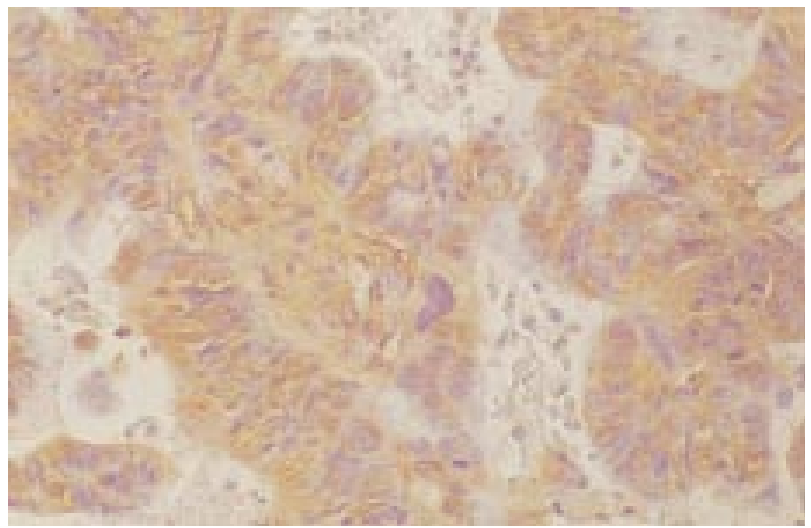

Figure 3. EGFR positivity in the original tumor of the PZX-20 line $(x$ 400)

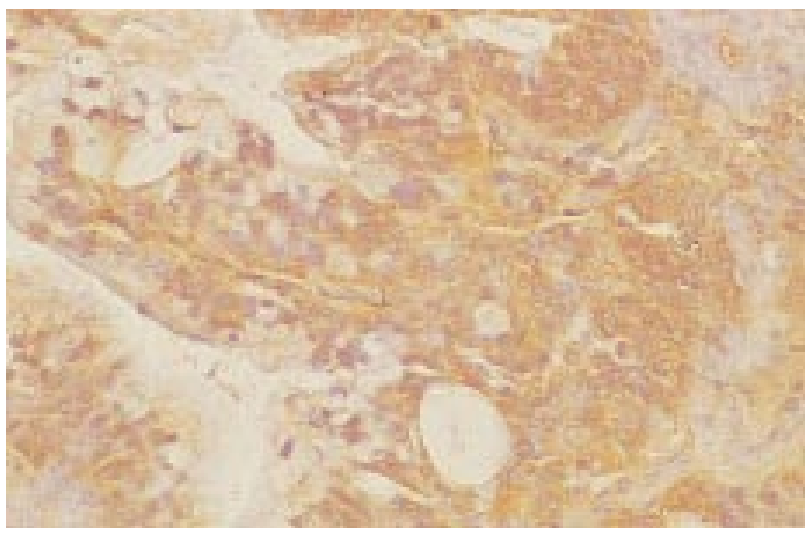

Figure 5. PZX-5 tumor line, 4th passage. The tumor cells are strongly positive for EGFR ( $x$ 400)
In the literature there is a plethora of reports dealing with bcl-2 in various malignant tumors including small cell lung cancer, ${ }^{24,37}$ soft tissue sarcomas, ${ }^{14}$ endometrial carcinoma, ${ }^{9,22}$ neuroblastoma, ${ }^{13}$ and ovarian cancer, ${ }^{36}$ but there are only a few articles on non-endocrine pancreatic

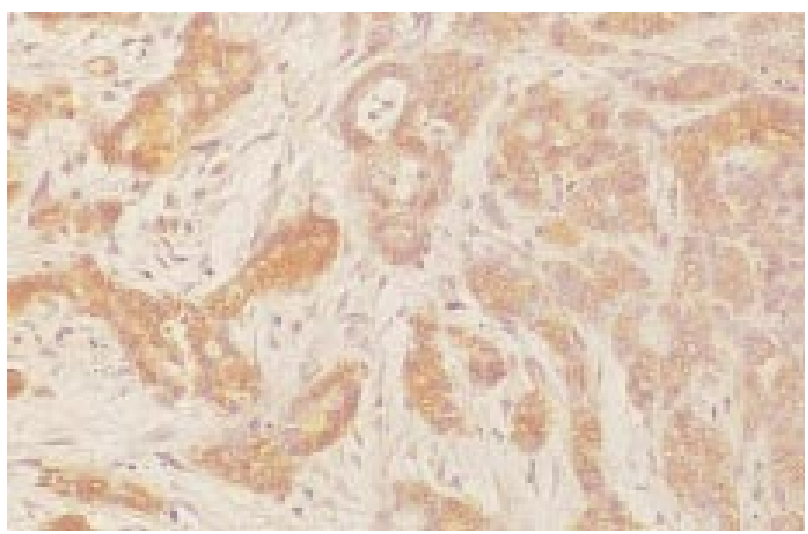

Figure 2. PZX-11, original tumor. The tumor cells express strong bol-2 immunoreactivity (x 100)

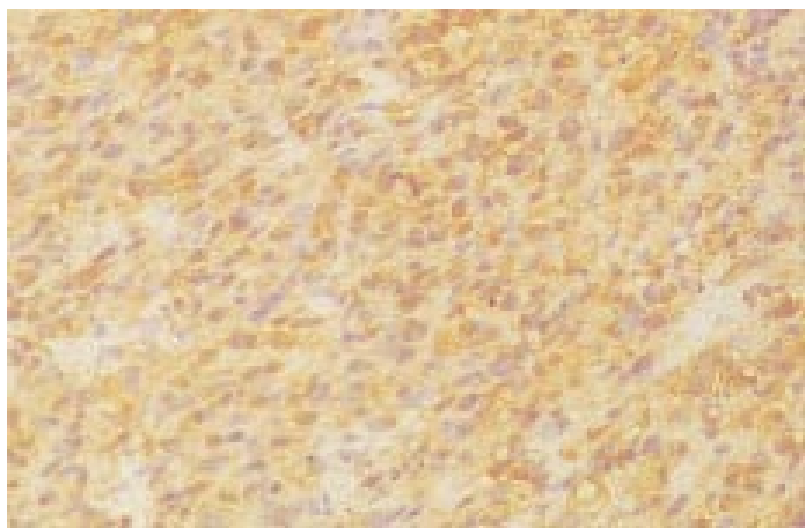

Figure 4. Pancreatic leiomyosarcoma xenograft (PZX-7), 5th passage. The tumor cells express strong bcl-2 positivity. $(x$ 400)

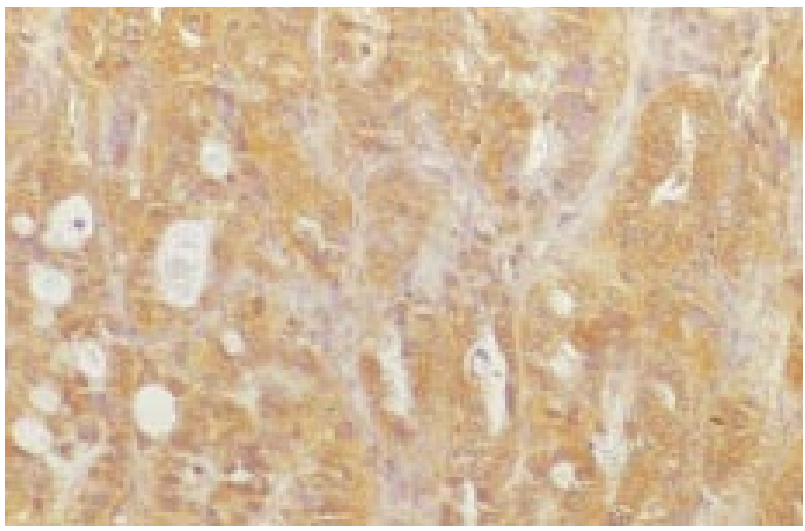

Figure 6. PZX-5 tumor line, 5th passage, after Sandostatin treatment. There is no change in the strong EGFR positivity (x 200) 

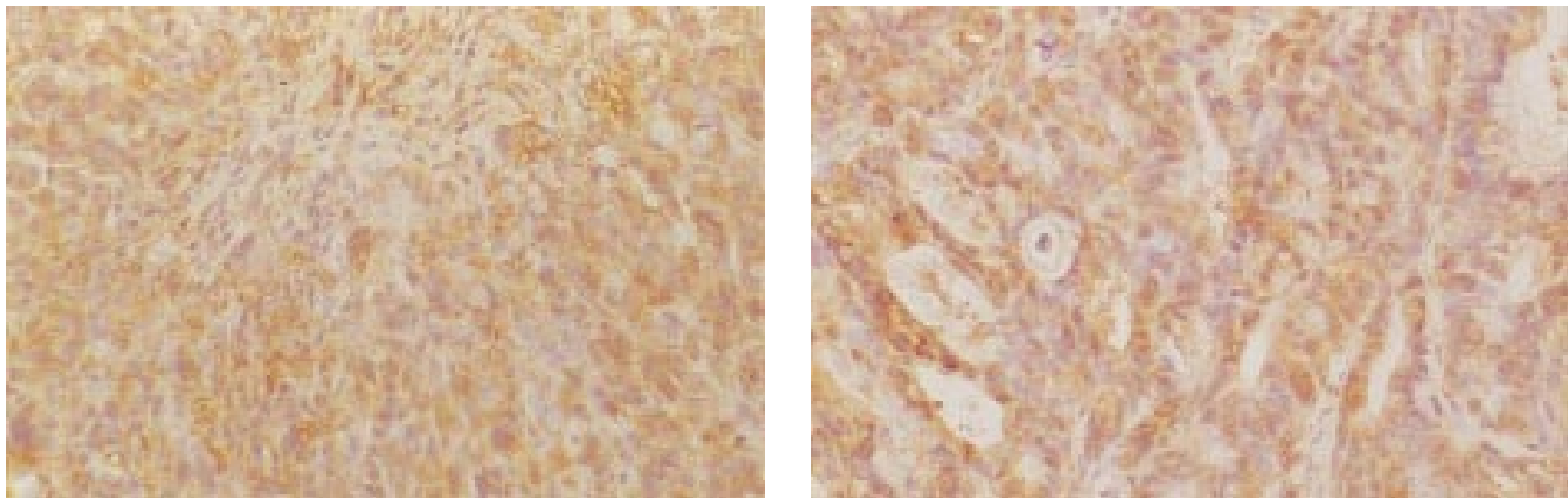

Figure 7-8. PZX-5 tumor line, 5th passage, after Sandostatin treatment. The majority of the tumor cells express bcl-2 positivity that was not present in the untreated controls (x 200)

carcinoma. ${ }^{11,15,23}$ In normal human pancreatic tissue bcl-2 positive cells are present in moderate number usually randomly distributed among the acinar and islet cells, and the ductal cells exhibit rare or no positivity. ${ }^{1,8}$ Human pancreatic cancer samples expressed $20-55 \%$ bcl-2 positivity, ${ }^{11,15,23}$ but the prognostic impact of bcl-2 is still not clear. Ohshio ${ }^{15}$ could not observe any survival benefit among patients with negative immunostaining, but, Mäkinen $^{11}$ and Sinicrope ${ }^{23}$ have found that the tumors with bcl-2 overexpression are less aggressive, especially the well differentiated carcinomas.

The growth of a malignant tumor is essentially determined by the balance between the cell loss and cell proliferation. Many proapoptotic and antiapoptotic mechanisms participate in these processes. One protein (e.g. bcl-2) can hardly be marker alone, since other proteins are able to modify its effect. ${ }^{19}$

Another reason that makes the interpretation of bcl-2 immunoexpression difficult is that it could be induced by a number of external factors. In rats the ligation of the pancreatic duct results in a significantly increased bcl-2 expression in the ductal cells when the acinar cells are gradually vanishing. ${ }^{32}$ Conversely, in human pancreatic cancer cell lines its expression was down-regulated after treatment with an exogenous cdk inhibitor (butyrolactone). ${ }^{33}$ Many well documented experiments clearly demonstrated that the bcl- 2 expression was also profoundly altered under hormonal effects. Uterine leiomyoma cells exhibited different expression in the different phases of menstrual cycle: progesterone caused an increase, while estrogen resulted in a decrease. ${ }^{12}$ Teixeira et al. have reported that estrogen administration to an estrogen-receptor positive human breast cancer cells (MCF-7) markedly induced the presence of the $8.5 \mathrm{~kb}$ bcl- 2 mRNA transcripts and this finding was accompanied by an increased resistance against adriamycin. ${ }^{27}$ Similarly, in a hormone dependent human prostatic cancer cell line an increased expression of bcl-2 protein was observed after androgen treat- ment. ${ }^{2}$ To our knowledge, however, the observation that a somatostatin analog can induce bcl-2 positivity in an originally bcl-2 negative pancreatic carcinoma has not been noticed earlier.

Although our finding is theoretically interesting, there are some questions to be answered. First, it reinforces again the earlier observations that human pancreatic cancer is responsive to hormonal manipulations. Secondly, in addition to steroid hormones, bcl-2 expression could also be induced by a somatostatin analog, a polypeptide. Thirdly, this expression of the bcl-2 may imply a "defense" of the pancreatic cancer cells against the "noxious" effects rendering the tumor cells more resistant to the hormonal treatment.

\section{Acknowledgment}

The author thanks Mr. Pal Szarvashegyi for his excellent technical contribution.

\section{References}

1. Bell K, Bronner MP, Pasha T, et al: Expression of proliferating cell nuclear antigen in gastrointestinal tract lesions and its relationship to bcl-2 expression. Pathobiology 64:91-98, 1996.

2. Berchem GJ, Bosseler M, Sugars LY, et al: Androgens induce resistance to bcl-2-mediated apoptosis in $\mathrm{LNCaP}$ prostate cancer cells. Cancer Res 55:735-738, 1995.

3. Bocsi J, Zalatnai A: Establishment and long term xenografting of human pancreatic carcinomas in immunosuppressed mice: Changes and stability in morphology, DNA ploidy and proliferative activity. J Cancer Res Clin Oncol 125:9-19, 1999.

4. Chester JF, Gaissert HA, Ross JS, et al: Pancreatic cancer in the Syrian golden hamster induced by N-Nitrosobis(2-oxopropyl) amine: cocarcinogenic effect of epidermal growth factor. Cancer Res 46:2954-2957, 1986.

5. Fisher WE, Doran TA, Muscarella II P, et al: Expression of somatostatin receptor subtype 1-5 genes in human pancreatic cancer. J Natl Cancer Inst 90:322-324, 1998.

6. Gansauge F, Gansauge S, Schmidt E, et al: Prognostic significance of molecular alterations in human pancreatic carcinoma 
- an immunohistochemical study. Langenbecks Arch Surg 383:152-155, 1998.

7. Gower WR jr, Risch RM, Godellas CV, et al: HPAC, a new human glucocorticoid-sensitive pancreatic ductal adenocarcinoma cell line. In Vitro Cell Developm Biol Anim 30A:151$161,1994$.

8. Hockenbery DM, Zutter M, Hickey W, et al: BCL-2 protein is topographically restricted in tissues characterized by apoptotic cell death. Proc Natl Acad Sci USA 88:6961-6966, 1991.

9. Kuwashima Y, Kobayashi Y, Kurosumi M, et al: Inverse correlation between bcl-2 expression and cell growth fraction in human endometrial adenocarcinoma tissue. Anticancer Res 17:3773-3776, 1997.

10. Lemoine NR, Hughes CM, Barton CM, et al: The epidermal growth factor receptor in human pancreatic cancer. J Pathol 166:7-12, 1992.

11. Mäkinen K, Hakala T, Lipponen P, et al: Clinical contribution of bcl-2, p53 and Ki-67 proteins in pancreatic ductal adenocarcinoma. Anticancer Res 18:615-618, 1998.

12. Matsuo H, Maruo T, Samoto T: Increased expression of Bcl-2 protein in human uterine leiomyoma and its up-regulation by progesterone. J Clin Endocrinol Metab 82:293-299, 1997.

13. Mejia MC, Navarro S, Pellin A, et al: Study of bcl-2 protein expression and the apoptosis phenomenon in neuroblastoma. Anticancer Res 18:801-806, 1998.

14. Nakanishi H, Ohsawa M, Naka N, et al: Immunohistochemical detection of bcl-2 and p53 proteins and apoptosis in soft tissue sarcoma: their correlations with prognosis. Oncology 54:238244, 1997.

15. Ohshio G, Suwa H, Imamura T, et al: An immunohistochemical study of bcl-2 and p53 protein expression in pancreatic carcinomas. Scand J Gastroenterol 33:535-539, 1998.

16. Poston GJ, Townsend CM jr, Rajareman S: Effect of somatostatin and tamoxifen on the growth of human pancreatic cancers in nude mice. Pancreas 5:151-157, 1990.

17. Qin Y, Ertl T, Groot K, et al: Somatostatin analog RC-160 inhibits growth of CFPAC-1 human pancreatic cancer cells in vitro and intracellular proliferation of cyclic adenosine monophosphate. Int J Cancer 60:694-700, 1995.

18. Redding $T W$, Schally $A V$ : Inhibition of growth of pancreatic carcinomas in animal models by analogs of hypothalamic hormones. Proc Natl Acad Sci USA 81:248-252, 1984.

19. Reed JC: Bcl-2 family proteins and their hormonal control of cell life and death in normalcy and neoplasia. Vitamins and Hormones 53:99-138, 1997.

20. Robertson JF, Watson SA, Hardcastle JD: Effect of gastrointestinal hormones and synthetic analogues on the growth of pancreatic cancer. Int J Cancer 63:69-75, 1995.

21. Rosenberg L, Barkun AN, Denis MH, et al: Low dose octreotide and tamoxifen in the treatment of adenocarcinoma of the pancreas. Cancer 75:23-28, 1995.

22. Saegusa M, Okayasu I: Bcl-2 is closely correlated with favorable prognostic factors and inversely associated with p53 protein accumulation in endometrial carcinomas: immunohistochemical and polymerase chain reaction/loss of heterozygosity findings. J Cancer Res Clin Oncol 123:429-434, 1997.

23. Sinicrope FA, Evans DB, Leach SD, et al: $\mathrm{Bcl}-2$ and $\mathrm{p} 53$ expression in resectable pancreatic adenocarcinomas: association with clinical outcome. Clin Cancer Res 2:2015-2022, 1996.
24. Stefanaki K, Rontogiannis D, Vamvouka C, et al: Immunohistochemical detection of bcl-2, p53, mdm2 and $\mathrm{p} 21 / \mathrm{waf} 1$ proteins in small-cell lung carcinomas. Anticancer Res. 18:1167-1173, 1998.

25. Szende B, Zalatnai A, and Schally AV: Programmed cell death (apoptosis) in pancreatic cancers of hamsters after treatment with analogs of both luteinizing hormone-releasing hormone and somatostatin. Proc Natl Acad Sci USA 86:1643-1647, 1989.

26. Takeda Y, Escribano MJ: Effects of insulin and somatostatin on the growth and the colony formation of two human pancreatic cancer cell lines. J Cancer Res Clin Oncol 117:416-420, 1991.

27. Teixeira C, Reed JC, Pratt MA: Estrogen promotes chemotherapeutic drug resistance by a mechanism involving $\mathrm{Bcl}-2$ protooncogene expression in human breast cancer cells. Cancer Res 55:3902-3907, 1995.

28. Uegaki K, Nio Y, Inoue Y, et al: Clinicopathological significance of epidermal growth factor and its receptor in human pancreatic cancer. Anticancer Res 17:3841-3847, 1997.

29. Upp JR, Olson D, Poston GJ, et al: Inhibition of growth of two human pancreatic adenocarcinomas in vivo by somatostatin analog SMS 201-995. Am J Surg 155:29-35, 1983.

30. Vidal C, Rauly I, Zeggari M, et al: Up-regulation of somatostatin receptors by epidermal growth factor and gastrin in pancreatic cancer cells. Mol Pharmacol 46:97-104, 1994.

31. Vinter-Jensen L, Juhl CO, Teglbjaerg PS, et al: Systemic treatment with epidermal growth factor in pigs induces ductal proliferations in the pancreas. Gastroenterology 113:1367-1374, 1997.

32. Wada $M$, Doi R, Hosotani $R$, et al: Expression of bcl-2 and PCNA in duct cells after pancreatic duct ligation in rats. Pancreas 15:176-182, 1997.

33. Wada M, Hosotani R, Lee JU, et al: An exogenous cdk inhibitor, butyrolactone-1, induces apoptosis with increased Bax/Bcl-2 ratio in p53-mutated pancreatic cancer cells. Anticancer Res 18:2559-2566, 1998.

34. Wang DG, Johnston $C F$, Buchanan KD: Oncogene expression in gastroenteropancreatic neuroendocrine tumors: implications for pathogenesis. Cancer 80:668-675, 1997.

35. Weckbecker G, Tolcsvai L, Liu R, et al: Preclinical studies on the anticancer activity of somatostatin analogue octreotide (SMS 201-995). Metabolism 41: Suppl. 2., 99-103, 1992.

36. Witty JP, Jensen RA and Johnson AL: Expression and localization of Bcl-2 related proteins in human ovarian cancers. Anticancer Res 18:1223-1230, 1998

37. Yan JJ, Chen FF, Tsai YC, Jin YT: Immunohistochemical detection of bcl-2 protein in small cell carcinomas. Oncology 53:6-11, 1996.

38. Zalatnai A, Bocsi J, Timár F, et al: Establishment and characterization of a new transplantable pancreatic cancer xenograft (PZX-5) in immunosuppressed mice. Internatl $\mathrm{J}$ Pancreatol 23:51-62, 1998.

39. Zalatnai A, Kovács M, Flautner L, et al: Pancreatic leiomyosarcoma. Case report with immunohistochemical and flow cytometric studies. Virchows Arch 432:469-472, 1998.

40. Zalatnai A, Schally AV: Treatment of the N-Nitrosobis/2-oxopropyl/amine-induced pancreatic cancer in Syrian golden hamsters with D-Trp-6-LH-RH and somatostatin analog RC-160 microcapsules. Cancer Res 49:1810-1815, 1989. 